\title{
DEXMEDETOMIDINE AND ESMOLOL ON PREVENTION OF HAEMODYNAMIC RESPONSE TO LARYNGOSCOPY AND TRACHEAL INTUBATION- A RANDOMISED PROSPECTIVE STUDY
}

\author{
Anupananda Choudhury1, Hiranya Kumar Saharia², Rajita Devi³, Sudip Mandal ${ }^{4}$ \\ ${ }^{1}$ Associate Professor, Department of Anaesthesia, Gauhati Medical College and Hospital, Guwahati. \\ ${ }^{2}$ Assistant Professor, Department of Anaesthesia, Gauhati Medical College and Hospital, Guwahati. \\ ${ }^{3}$ Nursing Officer, Critical Care Unit, Neigrimhs, Shillong. \\ ${ }^{4}$ Resident, Department of Anaesthesia, Gauhati Medical College and Hospital, Guwahati.
}

ABSTRACT
BACKGROUND
Laryngoscopy and tracheal intubation manifests as transient, but distinct tachycardia and hypertension due to exaggerated
sympathoadrenal response.
The aim of this study is to compare the efficacy of dexmedetomidine (Intravenous infusion at a dose of $1 \mathrm{mcg} / \mathrm{kg}$ ) and esmolol
(intravenous infusion at a dose of $1 \mathrm{mg} / \mathrm{kg}$ ) in blunting the haemodynamic response secondary to laryngoscopy and tracheal
intubation.

Settings and Design of Study- A prospective, randomised, double-blinded study in Gauhati Medical College and Hospital, Assam.

\section{MATERIALS AND METHODS}

All adult patients of both sex scheduled for elective surgery under general anaesthesia were included. They were selected by lottery method to divide into two groups, Group E and Group D with 30 cases in each group. Group E received $1 \mathrm{mg} / \mathrm{kg}$ esmolol diluted to $10 \mathrm{~mL}$ with normal saline and Group E received dexmedetomidine $1 \mathrm{mcg} / \mathrm{kg}$ diluted to $10 \mathrm{~mL}$ with normal saline as intravenous infusion over 10 minutes before induction of anaesthesia.

\section{RESULTS}

Results suggested that at 1 minute after laryngoscopy and intubation, in Group E the increase in heart rate was 7.66\% from the baseline which was statistically significant $(\mathrm{p}<0.05)$. In Group D the increase in heart rate from baseline was $1.90 \%$, which was statistically insignificant. At 3 minutes after intubation when both the groups were compared, the increase in mean heart rate was higher in Group E which was highly significant $(\mathrm{p}<0.001)$.

\section{CONCLUSION}

Both the drugs attenuated the pressure response. Of the two drugs administered, dexmedetomidine $1.0 \mu \mathrm{g} / \mathrm{kg}$ provides a consistent, reliable and effective attenuation of pressure responses when compared to esmolol $1.0 \mathrm{mg} / \mathrm{kg}$.

\section{KEYWORDS}

Haemodynamic Response, Tracheal Intubation, Laryngoscopy, Dexmedetomidine, Esmolol.

HOW TO CITE THIS ARTICLE: Choudhury A, Saharia HK, Devi R, et al. Dexmedetomidine and esmolol on prevention of haemodynamic response to laryngoscopy and tracheal intubation- a randomised prospective study. J. Evolution Med. Dent. Sci. 2017;6(72):5146-5152, DOI: 10.14260/Jemds/2017/1118

\section{BACKGROUND \\ Laryngoscopy and tracheal intubation have become an integral part of anaesthetic management and critical care since their description in 1921 by Rowbotham and Magill.[1] Circulatory response to laryngeal and tracheal stimulation in the form of tachycardia, hypertension and dysarrhythmia was known since 1940.[1,2] The principle mechanism behind the hypertension and tachycardia is the exaggerated sympathetic action due to increased catecholamine release. [3] The increase in heart rate and blood pressure is usually transient, variable and unpredictable.[3] It may not be of much significance in healthy individuals, but can be hazardous in those with hypertension, cardiac dysfunction, coronary artery disease or cerebrovascular disease.[4]}

Financial or Other, Competing Interest: None.

Submission 14-06-2017, Peer Review 24-08-2017,

Acceptance 31-08-2017, Published 07-09-2017.

Corresponding Author:

Dr. Hiranya Kumar Saharia,

Assistant Professor, Quarter No-APF-A-4,

Norkasur Hill, Gauhati Medical College,

Gauhati-32, Assam.

E-mail: sahariahiranya@gmail.com

DOI: $10.14260 /$ jemds $/ 2017 / 1118$
Dexmedetomidine, the pharmacologically active d-isomer of medetomidine (4,[5]-[1-(2,3-dimethylphenyl)-ethyl] imidazole is a highly specific and selective alpha-2 adrenoreceptor agonist. In recent studies, dexmedetomidine was shown to have clinically significant effects on anaesthetic requirement and haemodynamic responses induced by anaesthesia and surgery in patients. [5]

Since tachycardia appears to be associated more frequently with myocardial ischaemia than does with hypertension, an interesting approach towards attenuating cardiac responses to laryngeal stimulation is the use of betaadrenergic antagonists.[6] Among the beta-adrenergic antagonists, esmolol (methyl 3-4-[2-hydroxy-3- (isopropyl amino) propoxy-phenyl] propionate hydrochloride) is an effective option because it is ultra-short acting and can be administered intravenously.[7] Thus, this short acting betablocker appears quite suitable for use during a short lived stress such as tracheal intubation. Apart from its effect, it is also known to reduce the requirement for anaesthetic agents. ${ }^{[8]}$

In our Institute, esmolol is used commonly to blunt the haemodynamic response following laryngoscopy and intubation. Following the recent report in peer reviewed literature of usefulness of dexmedetomidine, we have started its use also. 


\section{Objectives}

To compare the efficacy of intravenous dexmedetomidine in a dose of $1 \mathrm{mcg} / \mathrm{kg}$ body weight with intravenous esmolol 1 $\mathrm{mg} / \mathrm{kg}$ body weight, both infused over 10 minutes, in blunting the haemodynamic response secondary to laryngoscopy and tracheal intubation.

\section{MATERIALS AND METHODS}

After obtaining an approval from Institutional Ethics Committee the study was started in Gauhati Medical College and Hospital, Assam. All adult patients of both sexes between ages 18 and 60 years, ASA status I and II and who were scheduled for elective ENT and General Surgery under general anaesthesia with endotracheal intubation were included. All patients were thoroughly examined and routine investigations were carried out. The patients who refused to consent, patients whose physical characteristics suggested difficulties in intubation (Mallampati grades III and IV), having history of alcohol abuse or drug allergies, pregnant and lactating patients and who were posted for emergency surgery were excluded from the study.

\section{Sample Size Calculation}

Since studies must be adequately powered to achieve their aims with economic, ethical and scientific reasons, appropriate sample size calculations were done at the design stage of the study. Gupta $\mathrm{HB}$ et al[9] while comparing heart rate (beats/min) between esmolol and dexmedetomidine found Heart Rate (10 mins after intubation) at $80.53 \pm 3.52$ and 74.73 \pm 2.94 respectively $(\mathrm{P}<.001)$. Using it as reference for present study, the pooled $\mathrm{SD}=3.23$ (beats $/ \mathrm{min}$ ) corresponding to difference of 5.8 (beats/min), JMP 10 (SAS Inc., NC, USA) was used to estimate sample size for $0.01 \%$ level of significance (99.99\% Confidence) and 95\% power. The sample size was estimated at 45 for two groups, i.e. 22.5 samples per group.

\section{Sample Size Adjustment}

However, in order to achieve further accuracy and avoid missing data, lost for followup or other unseen reasons, sample size was kept at 60 corresponding to sample size 30 for intravenous dexmedetomidine group and 30 for intravenous esmolol group.

The design selected was prospective, randomised, doubleblinded study. The samples of the study were selected by simple random sampling without replacement. Lottery was done to randomly select the subjects in Group E (30) and Group D (30). The name of patients, who fulfilled the inclusion criteria and who were available were written on a slip of paper and put in a bowl and mixed thoroughly. The investigator picked up slips blindfolded and they were the subjects for study, the first pick was taken for Group $\mathrm{E}$ and the second one was considered for Group D. Each time before drawing a slip, slips were mixed thoroughly in the bowl.

Group E received $1 \mathrm{mg} / \mathrm{kg}$ esmolol diluted to $10 \mathrm{~mL}$ with normal saline as intravenous infusion over 10 minutes before induction of anaesthesia.

Group D received dexmedetomidine $1 \mathrm{mcg} / \mathrm{kg}$ diluted to $10 \mathrm{~mL}$ with normal saline as intravenous infusion over 10 minutes before induction of anaesthesia.
After arrival of the patients to the operating room, ECG and heart rate were monitored continuously and non-invasive recording of systolic, diastolic and mean arterial pressure were started. An intravenous line was secured in patient's left forearm using 18-gauge intravenous cannula.

All the patients were pre-medicated with intravenous injection of glycopyrrolate $(0.2 \mathrm{mg})$, ondansetron, fentanyl (1 $\mathrm{mcg} / \mathrm{kg}$ ).

The patients were then pre-oxygenated with $100 \%$ oxygen for 3 minutes before induction with a properly fitting face mask. Anaesthesia was induced with injection propofol and administered slowly till the end point, i.e. loss of verbal contact. Injection succinylcholine was administered at a dose of $1.5 \mathrm{mg} / \mathrm{kg}$ body weight intravenously.

Direct laryngoscopy was done using rigid laryngoscopy with standard Macintosh blade. Intubation was done with appropriate size disposable, high-volume low-pressure cuffed endotracheal tube. After intubation, anaesthesia was maintained with oxygen: nitrous (1:3) and volatile anaesthetic isoflurane ( 0.7 minimum alveolar concentration) with a tidal volume of $8 \mathrm{~mL} / \mathrm{kg}$ and a rate of 12 - 15 breaths per minute. For maintenance of relaxation, injection vecuronium was administered according to body weight. Hypoxia and hypercarbia were avoided in all the cases by keeping the tidal volume constant $(8 \mathrm{~mL} / \mathrm{kg})$ and respiratory rate in a narrow range variation $(12-16 / \mathrm{min})$ to keep the end-tidal carbondioxide within $30-45 \mathrm{mmHg}$.

\section{Statistical Analysis}

Groups were compared for demographic data (age, sex, weight) and duration of laryngoscopy and intubation, and haemodynamic parameters (HR, SBP, DBP, MAP). Data was compiled in Microsoft Excel worksheet and unpaired t-test. Chi-square test was used to calculate statistical significance in the study groups. Graph Pad in Stat Software was used for performing statistical analysis. $\mathrm{P}<0.05$ was considered significant. Data are represented as mean and SD.

\section{RESULTS}

\section{Distribution based on Demographic Variables}

The demographic profile of the patients in terms of age, body weight, male: female ratio, ASA status, Mallampati class were comparable and there were no significant differences among the three groups $(\mathrm{P}>0.05)$.

\section{Mean Duration of Laryngoscopy and Intubation}

\begin{tabular}{|c|c|c|c|}
\hline & Group E & Group D & P-value \\
\hline Mean Time (Seconds) & 11.63 & 12 & \multirow{2}{*}{0.572} \\
\cline { 1 - 3 } SD & 2.32 & 2.71 & \\
\cline { 1 - 2 } Table 1. Showing Mean Duration of Laryngoscopy \\
and Intubation in Two Groups (P-value was \\
Calculated by Unpaired T-Test) \\
\hline
\end{tabular}

There was no statistically significant difference amongst the groups. (P value $>0.05$ ) with respect to duration of laryngoscopy and intubation.

\section{Patient Preparation}

The procedure was explained to the patient beforehand. 
Baseline Haemodynamic Parameters (Mean \pm SD)

\begin{tabular}{|c|c|c|c|c|c|}
\hline Parameters & Group E & SD & Group D & SD & P-value \\
\hline HR (BPM) & 83.4 & 9.8 & 81.9 & 8.3 & 0.525 \\
\hline SBP (mmHg) & 121.9 & 10.1 & 120.9 & 10.9 & 0.713 \\
\hline DBP (mmHg) & 77.1 & 7.4 & 76 & 7.6 & 0.572 \\
\hline MAP (mmHg) & 92.03 & 8.07 & 91.1 & 8.1 & 0.657 \\
\hline Table 2. Showing Baseline Haemodynamic \\
Parameters of Both Groups (P-Value was \\
Calculated using Unpaired T-Test) \\
\hline
\end{tabular}

The descriptive statistics suggests that the two groups are comparable with regard to baseline parameters heart rate (HR), systolic blood pressure (SBP), diastolic blood pressure (DBP) and mean arterial blood pressure (MAP). There was no statistically significant difference amongst the groups ( $\mathrm{p}$ value $>0.05)$.

Comparison of Mean Heart Rate in Group E and D (P-value Calculated using Unpaired T-Test)

\begin{tabular}{|c|c|c|c|c|c|}
\hline Time & Group E & SD & Group D & SD & P-value \\
\hline Baseline & 83.4 & 9.8 & 81.9 & 8.38 & 0.510 \\
\hline $\begin{array}{l}\text { After giving } \\
\text { Study Drug }\end{array}$ & 74.8 & 8.5 & 77.5 & 9.25 & 0.211 \\
\hline After Induction & 78.5 & 10.04 & 79.06 & 9.03 & 0.84 \\
\hline $\begin{array}{l}1 \text { Minute after } \\
\text { Intubation }\end{array}$ & 89.86 & 10.42 & 83.4 & 8.52 & 0.011 \\
\hline $\begin{array}{l}3 \text { Minutes after } \\
\text { Intubation }\end{array}$ & 91.9 & 11.28 & 79.5 & 8.007 & $<0.0001$ \\
\hline $\begin{array}{l}5 \text { Minutes after } \\
\text { Intubation }\end{array}$ & 87.5 & 10.08 & 76.6 & 7.71 & $<0.0001$ \\
\hline $\begin{array}{l}7 \text { Minutes after } \\
\text { Intubation }\end{array}$ & 85.6 & 10.7 & 72.96 & 7.42 & $<0.0001$ \\
\hline
\end{tabular}

Table 3. Showing Comparison of Mean HR in Group E and Group D (P-Value was Calculated using Unpaired T-Test)

The mean baseline heart rates are comparable in both the groups: Statistical difference being insignificant ( $p>0.05$ ).

After giving the study drug, the mean heart rate decreased in both the groups.
The decrease in the mean HR was more in Group E (10.31\%) when compared to Group D (5.37\%) after infusion of study drug. But the difference was not statistically significant $(p>0.05)$.

After induction of anaesthesia, the mean heart rates decreased in both the groups when compared with the baseline values, but were statistically insignificant ( $p>0.05$ ). Decrease in heart rates after induction of anaesthesia when compared with each other (Group E and Group D) were not statistically significant.

At 1 minute after laryngoscopy and intubation, heart rates were increased in both the groups from baseline. In Group E the increase in heart rate was $7.66 \%$ from the baseline, which was statistically significant ( $p<0.05$ ). In Group D the increase in heart rate from baseline was $1.90 \%$, which was statistically insignificant. When both the groups are compared, the increase in mean heart rate after laryngoscopy and intubation is found to be significantly high in Group E than in Group D (p $<0.05$ ).

At 3 minutes after intubation, the mean heart rate remained significantly higher in Group E (10.22\%) when compared to baseline $(p<0.05)$. There was a decrease in mean heart rate $(2.93 \%)$ from baseline in Group D, which was statistically insignificant $(\mathrm{p}>0.05)$. When both the groups were compared, the increase in mean heart rate was higher in Group E and was highly significant $(\mathrm{p}<0.001)$.

In Group E, the mean heart rate remained higher than baseline at 5 minutes after intubation, but was statistically insignificant ( $p>0.05)$. In Group D, there was a significant decrease in mean heart rate from baseline at 5 minutes after intubation $(\mathrm{p}<0.05)$. There was highly significant difference in the mean heart rate between the groups at 5 minutes after intubation.

In Group E, increase in mean heart rate produced by laryngoscopy and intubation returned to near baseline at 7 minutes after intubation ( $p>0.05$ ). In Group D, there was $10.98 \%$ decrease in heart rate from baseline at 7 minutes after intubation: Statistical difference being highly significant $(\mathrm{p}<$ 0.0001 ). When both groups were compared there was highly significant statistical difference in mean heart rate between the two groups at 7 minutes after intubation.

\section{Comparison of Systolic Blood Pressure in Group E and D}

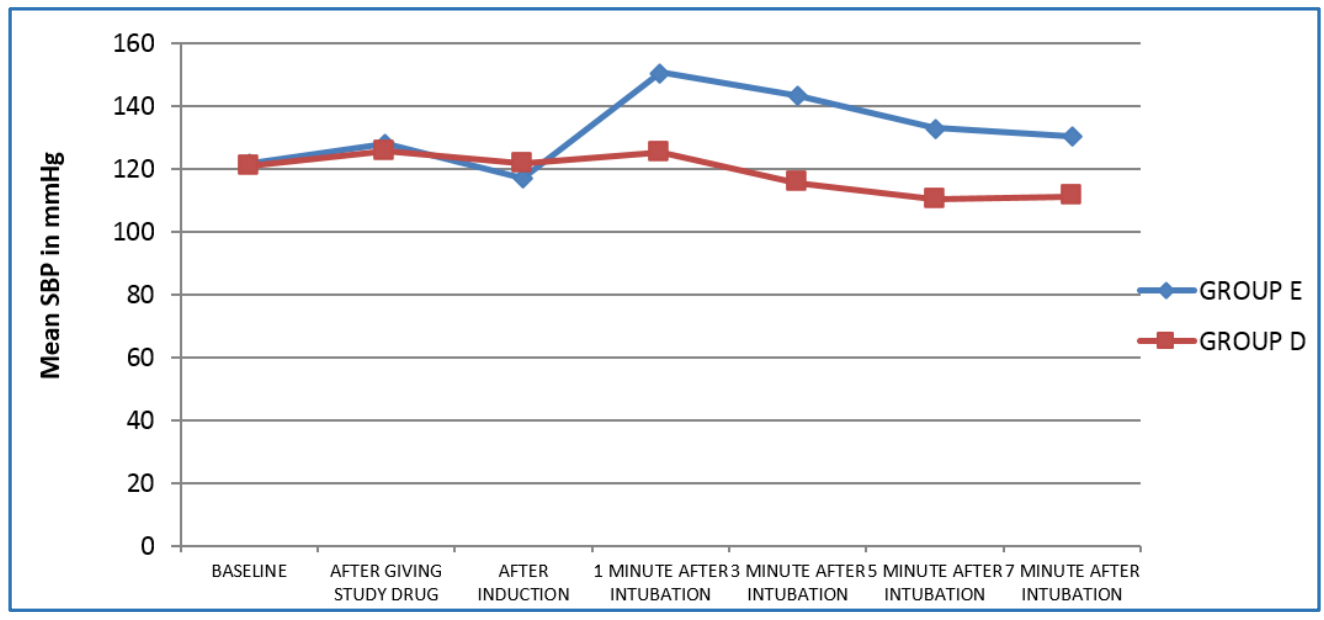

Figure 1. Showing Comparison of Mean Systolic Blood Pressure between Group E and Group D (P-value was Calculated using Unpaired T-Test) 
The SBP was comparable in two groups at baseline level. After infusion of study drug, mean systolic blood pressure increased in both the groups from baseline (by 5.08\% in Group E and by $4.03 \%$ in Group D). But it was statistically significant in Group E ( $p<0.05)$. There was no statistical significant difference of mean systolic blood pressure between the two groups when compared after infusion of study drug ( $p>0.05)$.

Mean systolic blood pressure decreased by $3.96 \%$ from baseline in Group E after induction of anaesthesia, which was statistically not significant ( $p>0.05$ ). In Group D, mean systolic blood pressure increased by $0.77 \%$ from baseline, but the increase was not statistically significant $(p>0.05)$. There was no significant difference of mean systolic blood pressure between the two groups when compared after induction of anaesthesia.

At 1 minute after intubation, mean systolic blood pressure increased in both the groups from baseline (by 23.75\% in Group E and by $3.80 \%$ in Group D). The increase was highly significant in Group E $(p<0.001)$ and the increase was not significant in Group D ( $p>0.05)$. The difference of mean systolic blood pressure between the two groups was highly significant $(\mathrm{p}<0.001)$ when compared at 1 minute after intubation.

Mean systolic blood pressure remained increased from baseline at 3 minutes after intubation in Group E, statistical difference being highly significant $(\mathrm{p}<0.001)$. There was a decrease in mean systolic blood pressure by $4.41 \%$ in Group D at 3 minutes after intubation, which was statistically not significant $(p>0.05)$. The difference of mean systolic blood pressure between the two groups was highly significant $(\mathrm{p}<$ 0.001 ) when compared at 3 minutes after intubation.

At 5 minutes after intubation, the mean systolic blood pressure remained high when compared with baseline in Group E and it was highly significant ( $\mathrm{p}<0.001$ ). In Group D, mean systolic blood pressure was decreased by $8.56 \%$ and was highly significant $(\mathrm{p}<0.001)$. The difference of mean systolic blood pressure between the two groups was highly significant $(p<0.001)$ when compared at 5 minutes after intubation.

The mean systolic blood pressure in Group E remained high at 7 minutes after intubation when compared with baseline and was highly significant $(\mathrm{p}<0.001)$. The mean systolic blood pressure was decreased significantly $(p<0.05)$ in Group D when compared with baseline. The difference of mean systolic blood pressure between the two groups was highly significant $(\mathrm{p}<0.001)$ when compared at 7 minutes after intubation.

\section{Comparison of Diastolic Blood Pressure in Group E and D}

\begin{tabular}{|c|c|c|c|c|c|}
\hline Time & Group E & SD & Group D & SD & P-value \\
\hline Baseline & 77.16 & 7.43 & 76 & 7.66 & 0.552 \\
\hline $\begin{array}{c}\text { After giving Study } \\
\text { Drug }\end{array}$ & 77.97 & 8.22 & 77.5 & 8.21 & 0.824 \\
\hline After Induction & 74.36 & 9.007 & 74.26 & 8.21 & 0.964 \\
\hline $\begin{array}{c}\text { 1 Minute after } \\
\text { Intubation }\end{array}$ & 88.6 & 8.59 & 79.7 & 8.24 & 0.0001 \\
\hline $\begin{array}{c}\text { 3 Minutes after } \\
\text { Intubation }\end{array}$ & 82.83 & 9.02 & 72.63 & 7.02 & $<0.0001$ \\
\hline
\end{tabular}

\begin{tabular}{|c|c|c|c|c|c|}
\hline $\begin{array}{c}\text { 5 Minutes after } \\
\text { Intubation }\end{array}$ & 76.26 & 6.85 & 69.33 & 6.72 & 0.0002 \\
\hline $\begin{array}{c}\text { 7 Minutes after } \\
\text { Intubation }\end{array}$ & 73.46 & 7.3 & 68.1 & 6.26 & 0.003 \\
\hline Table 4. Showing Comparison of Mean Diastolic \\
Blood Pressure between Group E and Group D \\
(P-value was Calculated using Unpaired T-Test)
\end{tabular}

Mean diastolic blood pressure was increased in both the groups (by $1.05 \%$ in Group E and by $1.97 \%$ in Group D) after infusion of study drug when compared with the baseline values. These increases in mean diastolic blood pressure were not statistically significant $(p>0.05)$. There was no significant difference in mean diastolic blood pressure between the two groups when compared with each other after infusion of study $\operatorname{drug}(\mathrm{p}>0.05)$.

There was a decrease in mean diastolic blood pressure in both the groups after induction of anaesthesia, but the decrease was not significant $(p>0.05)$. There was no significant difference in mean diastolic blood pressure between the two groups when compared with each other after induction of anaesthesia ( $p>0.05)$.

At 1 minute after intubation, there was increase in mean diastolic blood pressure in both the groups. The increase in mean diastolic pressure in Group E was highly significant when compared with the baseline mean diastolic blood pressure $(\mathrm{p}<0.001)$. The increase in mean diastolic blood pressure from baseline at 1 minute after intubation in Group D was not statistically significant $(p>0.05)$. When both the groups were compared at 1 minute after intubation, there was highly significant statistical difference of mean diastolic blood pressure between the two groups $(p=0.0001)$.

The mean diastolic blood pressure remained increased by 7.34\% from baseline in Group E at 3 minutes after intubation, which was statistically significant $(\mathrm{p}<0.05)$. There was a decrease in mean diastolic blood pressure by $4.43 \%$ from baseline in Group D at 3 minutes after intubation. When both groups were compared at 3 minutes after intubation, there was highly significant statistical difference of mean diastolic blood pressure between the two groups $(\mathrm{p}<0.001)$.

The mean diastolic blood pressure decreased in both the groups at 5 minutes after intubation when compared with baseline. The decrease was not statistically significant in Group E ( $p>0.05)$, but the decrease was highly significant in Group D ( $<$ 0.001). When both the groups were compared with each other, there was highly significant statistical difference of mean diastolic blood pressure between the two groups at 5 minutes after intubation $(\mathrm{p}<0.001)$.

At 7 minutes after intubation, the mean diastolic blood pressure decreased in both groups when compared with the baseline values (4.79\% in Group E and $10.34 \%$ in Group D). The decrease being statistically insignificant in Group E ( $p>$ $0.05)$, but was highly significant in Group D ( $<<0.001)$. When both the groups were compared with each other, there was significant statistical difference of mean diastolic blood pressure between the two groups at 7 minutes after intubation $(\mathrm{p}<0.05)$. 


\section{COMPARISON OF MEAN ARTERIAL PRESSURE}

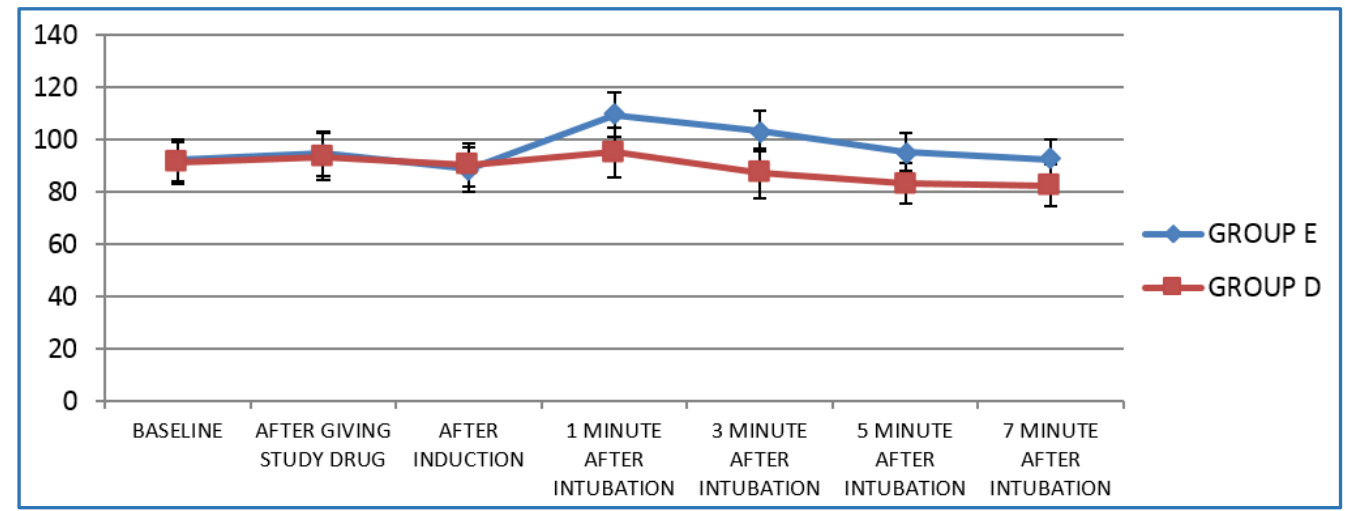

Figure 2. Showing Comparison of Mean MAP between Group E and Group D (P-value was Calculated using Unpaired T-Test)

The mean MAP increased from baseline in both the groups after infusion of study drug (by $2.82 \%$ in Group E and by $2.59 \%$ in Group D). But the decrease in mean MAP from baseline was statistically insignificant in both the groups $(p>$ 0.05). Mean MAP after infusion of the study drug was comparable in both the groups ( $\mathrm{p}>0.05$ ).

There was a decrease in mean MAP by $3.77 \%$ from baseline in Group E after induction of anaesthesia. This decrease was not statistically significant ( $p>0.05$ ). Similarly, there was a decrease in mean MAP in Group D by $1.10 \%$ from baseline, which was statistically insignificant. Mean MAP after induction of anaesthesia were comparable in both the groups ( $p>0.05$ ).

At 1 minute after intubation there was increase in mean MAP by $18.91 \%$ from baseline in Group E, which was highly significant $(p<0.001)$. There was an increase in mean MAP in Group D from baseline (4.34\%), which was statistically insignificant $(p>0.05)$. When both the groups were compared, there was a highly significant difference in mean MAP between the two groups ( $\mathrm{p}<0.001)$ at 1 minute after intubation.

Mean MAP remained increased by $11.98 \%$ from baseline at 3 minutes in Group E, which was highly significant $(p<0.001)$. There was a decrease in mean MAP by $4.38 \%$ from baseline in Group D, but it was not statistically significant ( $p>0.05)$. When both the groups were compared, there was a highly significant difference in mean MAP between the two groups $(p<0.001)$ at 3 minutes after intubation.

At 5 minutes after intubation, mean MAP becomes comparable with baseline ( $p>0.05$ ) in Group E. There was a highly significant decrease in mean MAP (by 8.47\%) from baseline $(p<0.001)$ in Group D. There was a highly significant difference in mean MAP between the two groups when compared at 5 minutes after intubation $(\mathrm{p}<0.001)$.

The mean MAP remained comparable with the baseline at 7 minutes after intubation in Group E ( $p>0.05)$. There was a highly significant decrease in mean MAP from baseline in Group D at 7 minutes after intubation. There was a highly significant difference in mean MAP between the two groups when compared at 7 minutes after intubation $(p<0.001)$.

\section{DISCUSSION}

Maintaining intraoperative haemodynamic stability is of utmost importance in anaesthesia care. Stress produced by laryngoscopy and intubation produce undesirable haemodynamic effects in the form of tachycardia and hypertension is usually well tolerated in healthy individuals, but it can be deleterious in patients with hypertension, cardiac dysfunction, coronary artery disease and neurovascular disease. ${ }^{[4]}$

In the present study, we compared the effect of intravenous infusion of dexmedetomidine with that of esmolol on haemodynamic attenuation of pressor response to laryngoscopy and intubation.

According to Splinter et al, marked fluctuations in haemodynamic responses are often seen in geriatric patients.[10] So, we selected the age range of $20-60$ years in our study.

The demographic data reveals that there was no significant difference among the two groups with respect to age, sex, weight or ASA physical status.

Comparison between two groups with respect to various studied parameters, i.e. heart rate (beats per minute), systolic blood pressure $(\mathrm{mmHg})$, diastolic blood pressure, mean arterial pressure reveals no statistical difference between two groups, as $\mathrm{p}>0.05$.

From the above discussion, it can be concluded that comparison of the effects of the studied drugs on attenuation of haemodynamic parameters in the present study is justified, as the demographic data and other patient variables and baseline haemodynamic parameters were all comparable and type of surgery, anaesthetic procedure and anaesthetic agents, equipment used were same between the two groups. Also, any confounding factor like patients with cardiovascular diseases and/or on drugs affecting cardiovascular functions were excluded from the study. The two groups differed only with respect to the study drugs used.

Yildiz $\mathrm{M}$ et al[11] found that pre-operative administration of a single dose of dexmedetomidine in a dose of $1 \mathrm{mcg} / \mathrm{kg}$ resulted in progressive increases in sedation, blunted the haemodynamic responses during laryngoscopy and reduced opioid and anaesthetic requirements.

Equipotent dose of dexmedetomidine and esmolol is not mentioned in any literature, so we selected the baseline dose of both the drugs used to attenuate the pressor response as per available literature.

According to Tan $\mathrm{PH}$ et al,[12] intravenous esmolol in a dose of $1 \mathrm{mg} / \mathrm{kg}$ is more effective than intravenous esmolol in a dose of $0.5 \mathrm{mg} / \mathrm{kg}$ in attenuating pressor response to laryngoscopy and intubation.

Based on the above studies, it was inferred that intravenous dexmedetomidine at $1 \mathrm{mcg} / \mathrm{kg}$ is needed for 
effective attenuation of haemodynamic response to intubation and intravenous esmolol at a dose of $1 \mathrm{mg} / \mathrm{kg}$ is needed to attenuate pressor response to laryngoscopy and intubation.

In the present study after infusion of the study drug, there was a decrease in mean heart rate in both the groups from baseline and also after induction of anaesthesia. In Group E, the mean heart rate decreased by $10.31 \%$ from baseline after infusion of study drug and decreased by $5.85 \%$ from baseline after induction of anaesthesia. In Group D, the mean heart rate decreased by $5.37 \%$ from baseline after infusion and by $3.46 \%$ from baseline after induction of anaesthesia. The reduction in heart rate was more in Group E.

After giving the study drug the mean SBP, mean DBP and mean MAP increased in both the groups. After induction of anaesthesia the mean SBP decreased by $3.96 \%$ in Group E and the mean SBP increased by $0.77 \%$ in Group D from baseline. And there was a decrease in mean DBP in both the groups after induction of anaesthesia. There was an increase in mean MAP after infusion of study drug in both the groups and there was a decrease in mean MAP (by $3.77 \%$ in Group E and by $1.10 \%$ in Group D) in both the groups after induction of anaesthesia. In Group E mean increase from baseline after infusion of the study drug was SBP by $5.08 \%$, DBP by $1.05 \%$ and MAP by $2.82 \%$. In Group D mean increase from baseline was SBP by $4.03 \%$, DBP by $1.97 \%$ and MAP by $2.59 \%$ after infusion of study drug. However, it was not statistically significant.

The decrease in heart rate and blood pressure in Group E may be due to bradycardia and myocardial depression esmolol produces. In Group D it was seen that there was an initial increase in the mean SBP and MAP, but decrease in HR and DBP.

In the present study the maximum increase in systolic blood pressure, diastolic blood pressure, mean arterial pressure and heart rate occurred at 1 minute and 3 minutes after intubation in Group E. In Group E the increase in mean SBP, DBP, MAP and HR was $23.75 \%, 14.82 \%, 18.91 \%$ and $7.66 \%$ respectively from the baseline at 1 minute after intubation. Whereas in the Group D, the increase in mean systolic blood pressure was $3.80 \%$, diastolic blood pressure was $4.78 \%$, mean arterial blood pressure was $4.34 \%$ and heart rate was $1.90 \%$ from baseline at 1 minute after intubation. The increase in haemodynamic parameters were statistically significant in Group E, but were not significant statistically in Group D.

Intergroup comparison shows that the increase in all the haemodynamic parameters studied was significantly higher in the Group E than the Group D, and was statistically significant.

At 3 minutes after intubation the increase in HR, SBP, DBP and MAP from baseline in Group E were $10.22 \%, 17.52 \%$, $7.34 \%$ and $11.98 \%$ respectively. These increases in haemodynamic parameters in Group E were statistically significant, whereas there was decrease in the studied parameters from baseline at 3 minutes after intubation in Group D. In Group D the decrease in HR, SBP, DBP and MAP were $2.93 \%, 4.41 \%, 4.43 \%$ and $4.46 \%$ respectively from baseline. This decrease was not statistically significant ( $p>$ 0.05).

In Group E, at 5 minutes and 7 minutes after intubation the mean HR returned to near baseline values $(p>0.05)$. At 5 minutes and 7 minutes after intubation, the mean SBP remained raised from baseline. The mean DBP and the mean MAP become comparable with the baseline at 5 minutes and 7 minutes after intubation. In Group D, all the studied haemodynamic parameters decreased from baseline at 5 minutes and 7 minutes after intubation. The decreases were statistically significant $(\mathrm{p}<0.05)$.

In this present study, intravenous dexmedetomidine infusion in a dose of $1 \mathrm{mcg} / \mathrm{kg}$ better attenuated the pressor response to laryngoscopy and intubation than intravenous esmolol infusion in a dose of $1 \mathrm{mg} / \mathrm{kg}$, both infused over 10 minutes before induction of anaesthesia.

Effective blunting of haemodynamic response of laryngoscopy and intubation in the dexmedetomidine group in our study is also supported by Basar H et al (2008).[13] They found that single intravenous injection of dexmedetomidine in a dose of $0.5 \mathrm{mcg} / \mathrm{kg}$ significantly blunted the pressor response to laryngoscopy and intubation when compared with control group.

The study results are supported by Reddy SV et al,[14] Srivastava VK et al[15] and Selvaraj et al..[16]

\section{CONCLUSION}

The study was carried out to compare the efficacy of esmolol and dexmedetomidine in blunting the haemodynamic response secondary to laryngoscopy and intubation. The incidence of hypertension and tachycardia following laryngoscopy and intubation were significantly lower in patients receiving intravenous dexmedetomidine infusion when compared with patients receiving intravenous esmolol infusion. The results of the study may be incorporated in clinical practice of anaesthesiology.

\section{REFERENCES}

[1] Brace R. Irritation of respiratory tract and its reflex effect on heart. Surgery Gynaecology Obstetrics 1940;7:157.

[2] Russel WJ, Morris RG, Frewin DB, et al. Change in plasma catecholamine concentrations during endotracheal intubation. Br J Anaesth 1981;53(8):8379.

[3] Kovac AL. Controlling the haemodynamic response to laryngoscopy and endotracheal intubation. J Clin Anaesth 1996;8(1):63-79.

[4] Fox EJ, Sklar GS, Hill CH, et al. Complications related to the pressor response to endotracheal intubation. Anesthesiology 1977;47(6):524-5.

[5] Naaz S, Ozair E. Dexmedetomidine in current anaesthesia practice-a review. J Clin Diagn Res 2014;8(10):GE01-GE04.

[6] Prys-Rroberts C. Anaesthesia and hypertension. Br J Anaesth 1984;56(7):711-24.

[7] Srivastava VK, Nagle V, Agrawal S, et al. Comparative evaluation of dexmedetomidine and esmolol on hemodynamic responses during laparoscopic cholecystectomy. J Clin Diagn Res 2015;9(3):UC01UC05.

[8] Bhawna SJSB, Lalitha K, Dhar P, et al. Influence of esmolol on requirement of inhalational agent using entropy and assessment of its effect on immediate postoperative pain score. Indian Journal of Anaesthesia 2012;56(6):535-41. 
[9] Gupta HB, Vyas S. A comparative study of efficacy of intravenous dexmedetomidine and intravenous esmolol for attenuation of stress response during laryngoscopy and endotracheal intubation. International Journal of Basic \& Clinical Pharmacology 2016;5(5):1803-8.

[10] Splinter WM, Cervenko F. Haemodynamic responses to laryngoscopy and tracheal intubation in geriatric patients: effects of fentanyl, lidocaine and thiopentone. Can J Anaesth 1989;36(4):370-6.

[11] Talke P, Li J, Jain U, et al. Effects of perioperative dexmedetomidine infusion in patients undergoing vascular surgery. The Study of Perioperative Ischemia Research Group. Anesthesiology 1995;82(3):620-33.

[12] Tan PH, Yang LC, Shih HC, et al. Combined use of esmolol and nicardipine to blunt the haemodynamic changes following laryngoscopy and tracheal intubation. Anaesthesia 2002;57(12):1207-12.

[13] Basar H, Akpinar S, Doganci N, et al. The effects of preanesthetic, single-dose dexmedetomidine on induction, hemodynamic and cardiovascular parameters. J Clin Anesth 2008;20(6):431-6.
[14] Reddy SV, Balaji D, Ahmed SN. Dexmedetomidine versus esmolol to attenuate the hemodynamic response to laryngoscopy and tracheal intubation: a randomized double-blind clinical study. Int J Appl Basic Med Res 2014;4(2):95-100.

[15] Srivastava VK, Agrawal S, Gautam SK, et al. Comparative evaluation of esmolol and dexmedetomidine for attenuation of sympathomimetic response to laryngoscopy and intubation in neurosurgical patients. J Anaesthesiol Clin Pharmacol 2015;31(2):186-90.

[16] Selvaraj V, Manoharan KR. Prospective randomized study to compare between intravenous dexmedetomidine and esmolol for attenuation of hemodynamic response to endotracheal intubation. Anesth Essays Res 2016;10(2):343-8. 